\title{
Innovative Characteristics Among Small And Medium Enterprises In (Johor) Malaysia
}

\author{
Mohammed Hayder Nadhim, Siti Sarah Omar, Ali Taha Oleiwia, Ganama Moustapha Gueme, \\ Dahlia Fernandez binti mohd Farid Fernandez
}

\begin{abstract}
Innovation is seen as a means that aids in promoting opportunities for new businesses to grow in the market. It has been proven to have a significant increase in SMEs as well as an expansion of business due to an implementation of innovation. Hence, SMEs are in competition among themselves in Malaysia even throughout the world, to improve their strategic innovation in order for them to boost productivity as well as sustain their competitive advantage. Thus, the objectives of this research are:(1) To identify the external business success factors being implemented by the SMEs in Johor. (2) To identify the internal business success factors being implemented by the SMEs in Johor. (3) To investigate the current level of innovative practices among SMEs in Johor. (4) To identify the relationship between external and internal factors with innovative practices among SMEs in Johor. Data was collected from 152 respondents of SMEs from all sectors in Johor. SPSS version 22 was used to analyze of the data. The findings confirmed that the survey instruments used were reliable. The findings enlighten that there is a significant positive relationship between external factors (Financial resource, Government supported developments, Market dynamics, and Academia-industry collaborations) on another hand, the internal factors (Organizational culture, and Management orientation) with innovation practices. The study also found that the level of innovation practices among SMEs in Johor was at a medium level. This study recommended to apply this study in other states within Malaysia and in other countries, Besides comparing innovative practices of locally managed SMEs and SMEs managed by foreign entities can increase our understanding of SME innovation practices. The study focused on SMEs, may better to examine large companies and identify whether they have similar outcomes.
\end{abstract}

Index Terms: Innovation, SMEs, External factors, Internal factors.

\section{INTRODUCTION}

Innovation function a vital role to support the growth of companies, in spite of the company's size, with provided strength economic value and enhance their competitive advantage(1). SMEs are considered as vital to the global economies which count as very significant and the SMEs are the massive section of global economies. Because of that importance, there are many investigators is seeking to understand SMEs(2). In the advanced economies, this concern has concentrated on SMEs expansion, a business establishes groups and entrepreneurship. These economies looking to the SMEs region for the establishment of bigger

Revised Manuscript Received on April 19, 2019.

Mohammed Hayder Nadhim, Faculty of Technology Management and Business, Universiti Tun Hussein Onn Malaysia, Johor, Malaysia.

Siti Sarah Omar,

Ali Taha Oleiwia,

Ganama Moustapha Gueme,

Dahlia Fernandez binti mohd Farid Fernandez, hiring, economic growth, and innovation (3).

Interpretation to Asia-Pacific Co-operation (APEC), 2010, in each state in the Asia-Pacific Collaboration, SMEs the rate of SMEs was above $90 \%$ of all business for the economies of generality countries of the world, the demand of the SMEs is rising and has become their known feature(4).

The strategic and innovative management literature emphasizes that this innovative action is a key prosperity factor that provides a competitive advantage and has a favorable effect on economic growth, responds to unmatched changes in the business environment and social, and generates novel awareness and technologies to make sure that innovation becomes these The top priority for emerging market companies is that existing knowledge about innovation in the Johor Research Area remains to hesitate or at least needs to be confirmed(5).

Research on SMEs innovative and business growth in Malaysia is very limited(6). The flaws in the literature are confined to empirical research to identify and quantify the factors affecting SMEs' innovative practices in the market environments and therefore is considered as necessary to solve the challenges faced by SMEs(7).

These SMEs face competition from large companies to enter the local market, hoping to gain more market share. Therefore, through innovation, it would enhance competitive advantage and provide SMEs with wider opportunities and channels in the local environment (8). According to comparative research showing that the level of innovation among Malaysian companies was lower than high-income countries and even with middle-income countries despite the implementation of various initiatives to establish a national innovation system to facilitate cooperation. (9).

(10) and many other researchers such as (11) and (6) stated that further research on marketing innovation is needed especially on improvement and strategies to increase the level of innovative practices among Malaysian firms. Moreover, very little is recognized about the extent and sort of innovation that happen at the company level and the factors that enable it (12).

Therefore, this study will provide a better understanding of internal and external environmental determinants and to identify the level of innovation of SMEs in Malaysia. In its seek to survive and compete for more in more effectively, it

Published By

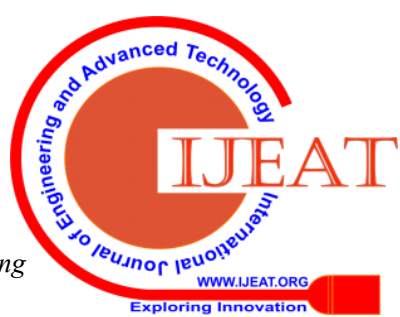


is important that companies hold to innovate and continue to offer new products and best quality (13).

Specially, the research objectives are as follows:

- To identify the level of external business success factors being implemented by the SMEs in Johor.

- $\quad$ To identify the level of internal business success factors being implemented by the SMEs in Johor.

- To investigate the current level of innovative practices among SMEs in Johor.

- To identify the relationship between external and internal factors with innovative practices among SMEs in Johor.

\section{LITERATURE REVIEW}

\section{A. Innovation Concept}

Innovation has been conceptualized in many ways with various definitions Innovation is a process that includes the generation new ideas or practices inside an organization then adapting these ideas and carry out them. (14) Define innovation as a process of transforming opportunities into new ideas, putting them into practice, and using them widely to see innovation as a concept of a common dimension process. According to (15) they mentioned that the innovation cover five aspects, such as introducing new products or quality to create quality products; introducing new production methods, including new methods to deal with commodity innovation processes; opening up new market innovations; invading new sources of materials to supply raw or intermediate inputs Innovation; and the implementation of a new organization for the organization of innovative industries.

(16) They are identified innovation capabilities as an organization's ability to compete with competitors, apply knowledge, skills and collective resources to creative activities related to new products, processes, services, management, marketing or business regulation to create value for the company or stakeholders.

\section{B. Small and Medium-Sized Enterprises (SMEs)}

According to (17) the definition of SMEs may vary from country to country, it also may be different within a country itself due to the differences in the business sector. The World Business Council for Sustainable Development (WBCSD) report (2007) mentioned that there is no generally fixed definition of SMEs (18). Some studies explain them in term of their total income, however, others use the number of workers as an indicator.

National SME Development Council (NSDC) in 2013 was given the new definition to SMEs in Malaysia as follows in Table I.
Table I. New definition of SMEs in Malaysia by size of operation.

\begin{tabular}{|c|c|c|}
\hline Category & Small & Medium \\
\hline $\begin{array}{l}\text { Manufact } \\
\text { uring }\end{array}$ & $\begin{array}{l}\text { RM 300,000 - } \\
\text { RM 15million. }\end{array}$ & $\begin{array}{l}\text { RM } 15 \text { million } \\
\text { RM } 50 \text { million }\end{array}$ \\
\hline
\end{tabular}

\begin{tabular}{llll} 
& $\begin{array}{l}\text { Full-time } \\
\text { employees }\end{array}$ & $5-75$ & $75-200$ \\
\hline $\begin{array}{l}\text { Services } \\
\text { \& others } \\
\text { sectors }\end{array}$ & Income & $\begin{array}{l}\text { RM 300,000 - } \\
\text { RM 3 million. }\end{array}$ & $\begin{array}{l}\text { RM 3 million } \\
\text { RM 20 million }\end{array}$ \\
& $\begin{array}{l}\text { Full-time } \\
\text { employees }\end{array}$ & $5-30$ & $30-75$ \\
\end{tabular}

Sources: (NSDC) (SME Corp. Malaysia, 2013).

SMEs considered important in the economy of Malaysia, and play an essential role in its growth (4). In the Malaysian economy, SMEs play an important role and are deemed to be the cornerstone of business growth in the country (19). The future development of Malaysia looks to depend to a large extent on the development of SMEs, which are essential for achieving the 2020 vision.

The future development of Malaysia seems to depend to a large extent on the development of SMEs, which are essential for achieving the 2020 vision and becoming fully developed and becoming an in industrialized country by 2020, Malaysia will develop into an industrialized country use the advantages of the country to overcome the weaknesses of SMEs (4).

\section{The External Factors That Drive The Success Of SMES}

The external factors that have significant impacts on the company behavior to innovate, whether to enhance or prevent innovative practices. (20) and other researchers such as (21) they suggested a number of the external factors that impact on the innovation practice among companies that factors contain (Financial resource, Government supported developments, Market dynamics, and Academia-industry collaborations).

\section{Financial Resources}

This notion is considered a funding provision. Companies will be able to innovative and seeking best resolutions while consider funds are obtainable (22).

(23) argues that the reason for this influence is that SMEs more frequently, financing sources for SMEs to get social capital or the development and introduction of new services and products in the market is one of the main seniority. SMEs facing difficulties to develop new product or service, one of these difficulties is the lack of financial resource (24). The government can play a big role to enhance the innovation practices among the companies through funding support to the companies that innovate new products (22). The hypothesis that can be built in the relationship between Financial Resources variable with innovation practices is as follows: 


\section{Hypothesis 1A:}

Financial Resources will have a significant positive impact on a company's innovation practices.

\section{Government Supported Developments}

This notion is considered as rules, formal corroboration, and infrastructure. Mostly policy of the government to support innovation can catalyze the market and business environment leads to innovation (25).

The government role was necessary to develop policies and motivations to develop their ability to improve national competitive advantage and industrial improvement, allowing companies to develop strong competitive innovations at the global and local levels(26).

Furthermore, innovation strategy can be a variety of policy behaviors to enhance the number and capacity of creative practices to succeed, and there is a need for sustained foresight, policy expansion, enforcement and supervision (27). The hypothesis that can be built in the relationship between Government Supported Developments variable with innovation practices is as follows:

\section{Hypothesis 1B:}

Government Supported Developments will have a significant positive impact on a company's innovation practices.

\section{Market Dynamics}

this notion clarifies the competition situation in the market among the companies. Markets with competitive environments show greater $\mathrm{R} \& \mathrm{D}$ intensity and faster innovation rates than markets that faceless competitive pressures. In addition, the company competes for a steady flow of rewards obtainable only to the first company offering innovation (28). The greater competition of the market in the past was considered beneficial for market action (29). Changes in market situation give companies greater opportunities to innovate and follow unfulfilled demands (30).

Good competition in the market, both in the domestic market and abroad is vital to stimulate market efficiency and corporate productivity, allowing companies that produce the necessary products and services to survive(26). The hypothesis that can be built in the relationship between Market Dynamics variable with innovation practices is as follows:

\section{Hypothesis 1C:}

Market Dynamics will have a significant positive impact on a company's innovation practices.

\section{Academia-Industry Collaborations}

This notion is deemed as reaching to talents, providing ideas, and transferring technologies. A company is always seeking modern knowledge as a path to keep innovation (31).

The relation among companies and academic organizations can function a significant role in all activities since product research and evolution to choices on firm strategy, But just if you can know how these relations work (32).

It can be critical for SMEs with narrow resources and abilities (33). Academic cooperation can help the company gain access to knowledge, talent, and contractual technical research, leading to greater innovation (22).

(34) discussed, Sometimes, the company needs access to relevant research to develop knowledge and skills when developing products and services. Collaboration in the academic field allows the company to reach talents, knowledge, technical knowledge and contract research that leads to greater innovation. Further, companies are encouraged to set close relationships with academic organizations intellectually and physically to keep continuous relationships that gain the benefits of talent employment, technology transfer, R \& D ability and stimulate innovation. (35). The hypothesis that can be built in the relationship between Academia-industry Collaborations variable with innovation practices is as follows:

\section{Hypothesis 1D:}

Academia-industry Collaborations will have a significant positive impact on a company's innovation practices.

\section{The Internal Factors that Drive The Success Of SMEs}

The internal determining factors are the factors that can impede the ability of the company to innovate and strengthen the behavior of innovators (36). The previous literature identified servile internal determinants of the company to develop the innovation practices (37). that include (Management Orientation, and Organizational Culture).

\section{Management Orientation}

This notion has investigated the character of the management and strategic guidance of the company. SMEs generally as a mirror of the managers or owners personality characteristics who have the ability to affect daily operations and reflect the strategic tendency and management practices of companies (34).

(37) discussed, The managers or owner of SMEs are nearer to work and, therefore, can make quick decisions and leading innovation. Further, Unlike large companies, SMEs generally reflect managers or owner who have the ability to effect its operations every day (38).

The management orientation looks to function a vital role in identifying and supporting the company's assessment to generate or adopt the innovation with different management strategies that differ in the way they are implemented and their innovative behaviors, understanding the management of environmental conditions plays an important role in how to select and to address the situations of these environmental (39). The context of SMEs, strategic companies oriented to innovation related to prospectors are more innovative with improved technical situations, followed by strategic companies oriented to the customer and strategic companies oriented to modernization (27). The hypothesis that can be built in the relationship between Management Orientation variable with innovation practices is as follows: 


\section{Hypothesis $2 A$ :}

Management Orientation will have a significant positive impact on a company's innovation practices.

\section{Organizational Culture}

This notion is linked to organizational knowing processes, flexible practices, designs. Organizational culture and internal learning can motivate innovation, provide workers the space to make mistakes, take risks, and make learning opportunities (27).

(40) Argues that a company that integrates innovation into its organizational culture and management process can achieve long-term success. To encourage innovation in the further, the knowledge previously available in the company must be identified, clarified and correctly understood and implemented innovations in a specific area (41). Learning inside the firm can improve the innovative of companies and their capability to recognize innovative opportunities, including different learning that provide increased and intermittent skills and techniques, and supports the institutionalization of innovation (42). The hypothesis that can be built in the relationship between Organizational Culture variable with innovation practices is as follows:

\section{Hypothesis 2B:} impact on a company's innovation practices.

\section{E. Research framework}

Basis on the previous literature that uses content analysis and theoretical bases, this work has developed a conceptual framework to inform and establish objectives. Which is adapted from (43) Thus, the current study examines the relationships between a set of independent and dependent.

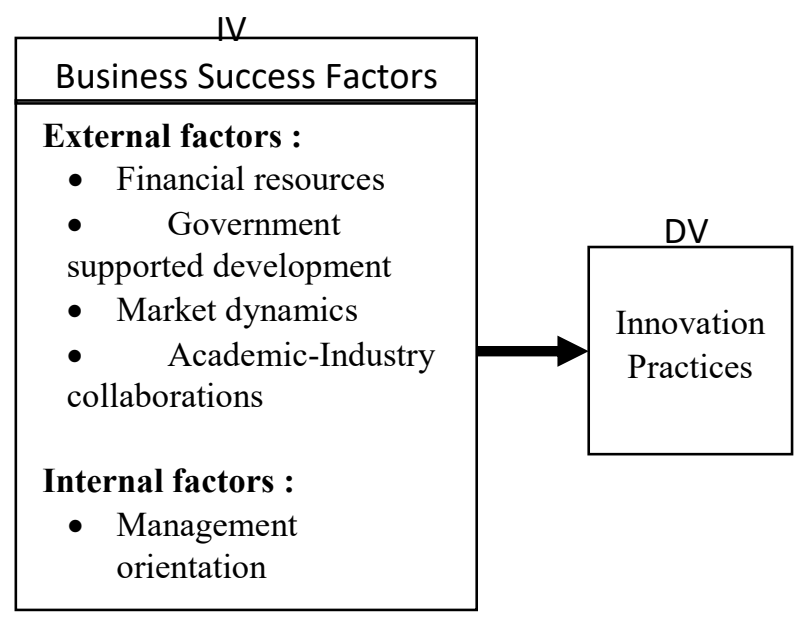

Fig.1. Research Framework

\section{METHODOLOGY}

There are two methods were used in this research to collect the data, the primary data collected by direct contact with respondents through questionnaires. While the secondary data collected from the existing data and obtained from published journals, dissertations, Internet information, published research, conference books, and documents. All these resources are used to support this research. In this
Organizational Culture will have a significant positive

study, the population is SMEs in Johor according to SMEs Corp. Malaysia there are 6500 SMEs in Johor. Based on (44), the required number of the respondent is 364 in orders to generalize the whole population of Johor SMEs.

This research is based on a questionnaire to identify the innovation development activities in Johor market. The questionnaire form is divided into four main sections. Part A is the demographic information while part $\mathrm{B}$ is for the external factors that are divided into four subsections ( B1 Financial Resources, B2 Government Supported Developments, B3 Market Dynamics, B4 AcademicIndustry Collaborations). Whereas part $\mathrm{C}$ is the internal factors that divided into two subsections ( $\mathrm{C} 1$ Management Orientation and C2 Organizational Culture ). The last part D covered the depended variable (Innovation practices).

In this study, a quantitative data collection was performed by using online Google document that was sent to SMEs through email the hardcopy of the questionnaire was distributed physically to achieve the acceptable rate of the respondent. However, the total collection of the returned questionnaire was only 152 sets with $41.75 \%$ of response rate. The collected data were analyzed by using IBM Statistical Packages for Social Science (SPSS) version 22.0. A Descriptive analysis and correlation analysis was used.

\section{DATA ANALYSIS AND FINDINGS}

\section{A. Reliability Analysis}

In assuring the reliability of this research, a reliability test was done during a pilot study and also in the actual study. All the elements on the questionnaire were tested for reliability through Alpha Cronbach coefficient to evaluate the internal consistency of each scale. items for each main constructs. The questionnaire constructed is considered acceptable when the coefficient of Cronbach's Alpha is more than 0.6 (45).

Therefore, the research can be conducted. On the other hand, the researcher needs to revise the questionnaire if the coefficient of Cronbach's Alpha is less than 0.6 due to the reason that there might be redundant or unclear questions in the questionnaire.

The Cronbach's Alpha for the pilot study was 0.851 . Questionnaires had been distributed to 30 respondents in order to test the level of reliability. Since the Cronbach's Alpha for the pilot study was 0.851 , the research instrument used in this study is considered good and reliable. Alpha value for reliability testing performed for all the elements in the questionnaire used in this study. The overall Cronbach's Alpha obtained is 0.902 . Therefore, can be said that the overall Cronbach's Alpha for all the elements in the questionnaire used in this study was having an "Excellent \& Effective" reliability level.

\section{B. Demographic Analysis}

The demographics data are shown in Table II below. With respect to gender, there was a $45.4 \%$ (69) respondents were male, while $54.6 \%$ (83) respondents were female. The age analysis of respondents majority of the respondents was

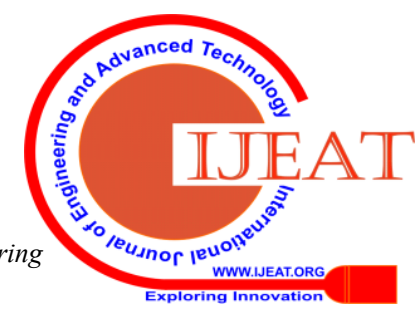


from age ranged between 20 -30 years old which were 69 respondents $(45.4 \%)$. and from $31-40$ years were a total of 41 respondents $(27 \%)$, and $21.7 \%$ (33 respondents) was between 41-50 years. The group from 51-65 recorded 3.9\% (6) and $1.3 \%$ (2 respondents) were under 20. More than 65 years with $0.7 \%$ ( 1 respondent).

The level of education attained from the respondents were Diploma degree which recorded a total of 52 respondents $(34.2 \%)$. The second highest number was (Higher Diploma/Bachelor holder) which were 51 respondents (33.6\%). Professional Certificate/Training recorded 19 (12.5\%). The Master and Doctorate level were14 of the respondent $(9.3 \%)$. Meanwhile, there were 5 respondents $(3.3 \%)$ from this at Primary/ Elementary school level. 2 of the respondent $(1.3 \%)$ they have no formal education.

Respondent's role in the firm showed the majority were 37 Supervisor/Manager (24.3\%) and the Officer/Assistant 32 respondents $(21.1 \%)$. The third group were (30) Owner /Managing Director/General Manager (19.7\%) and also Chief

Officer.

(Execute/Strategy/Technology/Science/Finance/Sales/Marke ting) were the same in third-ranked 30 respondents $(19.7 \%)$. The minority was Director/Head/Senior Manager 23 respondents $(15.1 \%)$.

The sector of respondent's firm, the majority of the respondents which total of $69(45.4 \%)$ were from the Service sector. Next, the Manufacturing sector which was $41(27 \%)$, a Trading sector which was $22(14.5 \%)$. On the other hand Construction sector which was 20 respondent $(13.2 \%)$.

Table II. Demographic An

\begin{tabular}{|c|c|c|c|}
\hline & & $\mathrm{F}$ & Percentage \\
\hline \multirow{3}{*}{ Gender } & Male & 69 & 45.4 \\
\hline & Female & 83 & 54.6 \\
\hline & Total & 152 & 100 \\
\hline \multirow{7}{*}{ Age } & Less than 20 years & 2 & 1.3 \\
\hline & 20 to 30 years & 69 & 45.4 \\
\hline & 31 to 40 years & 41 & 27.0 \\
\hline & 41 to 50 years & 33 & 21.7 \\
\hline & 51 to 65 years & 6 & 3.9 \\
\hline & More than 65 years & 1 & 0.7 \\
\hline & Total & 152 & 100 \\
\hline \multirow{8}{*}{$\begin{array}{l}\text { Education } \\
\text { Level }\end{array}$} & No formal education & 2 & 1.3 \\
\hline & Primary school & 5 & 3.3 \\
\hline & Secondary school & 9 & 5.9 \\
\hline & Certificate/Training & 19 & 12.5 \\
\hline & Certificate/ Diploma & 52 & 34.2 \\
\hline & HigherDiploma/Bachelor & 51 & 33.6 \\
\hline & Masters / Doctorate & 14 & 9.3 \\
\hline & Total & 152 & 100 \\
\hline \multirow{8}{*}{ Role } & Managing & & \\
\hline & Director/General & 30 & 19.7 \\
\hline & Manager/Owner & & \\
\hline & $\begin{array}{l}\text { Chief Officer (Strategy } \\
\text { /Finance /Marketing) }\end{array}$ & 30 & 19.7 \\
\hline & Officer/Assistant & 32 & 21.1 \\
\hline & Supervisor/Manager & 37 & 24.3 \\
\hline & $\begin{array}{l}\text { Director/Head/Senior } \\
\text { Manager }\end{array}$ & 23 & 15.1 \\
\hline & Total & 152 & 100 \\
\hline \multirow{5}{*}{ Sector } & Manufacturing & 41 & 27.0 \\
\hline & Construction & 20 & 13.2 \\
\hline & Service & 69 & 45.4 \\
\hline & Trading & 22 & 14.5 \\
\hline & Total & 152 & 100 \\
\hline
\end{tabular}

\section{Descriptive Analysis}

Descriptive analysis is used to describe the data and characteristics about the population or phenomenon being studied (46). In this study, data were analyzed to identify its mean. Mean value is used to describe the average number of respondents who agreed on the factors influencing respondents engagement that had been identified in the literature review. The mean ranking of each item was analyzed in order to determine its central tendency. The central tendency level will identify whether the items are in the range of low, medium or high.

1. Findings of Objective 1 ( To identify the level of external business success factors being implemented by the SMEs in Johor )

The external factors that determined in this study were (Financial resource, Government supported developments, Market dynamics, and Academia-industry collaborations).In General, the mean analysis conducted has shown that two of the factors were considered in the high central tendency. Moreover, two of the factors were considered in the medium central tendency. Based on Table III which shows the external business success factors level in the SMEs in Johor. The average mean for all the factors was medium which it was 3.622. The highest mean was 3.772 for the AcademicIndustry Collaborations and the lowest mean was for Financial Resources which was only 3.462.

Table III. Summary of Average Mean For External Variables

\begin{tabular}{llll}
\hline Variables & Mean & $\begin{array}{l}\text { Mean } \\
\text { Interpretation }\end{array}$ \\
\hline Academic-Industry & 3.772 & High \\
Collaborations & 3.682 & High \\
Market Dynamics & Supported & 3.574 & Medium \\
Government & 3.462 & Medium \\
Developments & & 3.622 & Medium \\
Financial Resources & & \\
Total & & \\
\hline
\end{tabular}

2. Findings Of Objective 2 ( To identify the level of internal business success factors being implemented by the SMEs in Johor )

The internal factors that determined in this study were (Organizational Culture and Management Orientation). In General, the mean analysis conducted has shown that the factors were considered in the high central tendency. Based on Table IV which shows the internal business success factors level in the SMEs in Johor. The average mean for all the factors was medium which it was 3.829. The highest mean was 3.912 for the Organizational Culture factors. On the other hand, the second factors ( Management Orientation ) also were high it comes with mean 3.746. 
International conference on Recents Advancements in Engineering and Technology (ICRAET-18) |15th and 16th March 2019|Siddhartha Institute of Technology \& Sciences, Telangana, India.

Table IV. Summary of Average Mean For Internal Variables.

\begin{tabular}{llll}
\hline Variable & Mean & $\begin{array}{l}\text { Mean } \\
\text { Interpretation }\end{array}$ & Score \\
\hline Organizational Culture & 3.912 & High & \\
Management Orientation & 3.746 & High & \\
Total & 3.829 & High \\
\hline
\end{tabular}

3. Findings Of Objective 3 ( To investigate the current level of innovative practices among SMEs in Johor)

In section ( D ) of the questionnaire there 6 questions that asked the respondents about their firms, if introduces a Number of new products Services, processes and creativity in their business processes, development of new sectors in the market, the use of new marketing methods, the development of new ways to establish relationships with customers and the expenditure of resources in the creation of many new products, services or new processes. Table V shows the summary means of the current level of innovative practices among SMEs in Johor according to the respondent's answer.

Table V. Summary of Average Mean For current level of innovative practices.

\begin{tabular}{llll}
\hline Variables & Mean & $\begin{array}{l}\text { Mean } \\
\text { Interpretation }\end{array}$ \\
\hline $\begin{array}{l}\text { current level } \\
\text { innovative practices }\end{array}$ & of & 3.531 & Medium \\
\hline
\end{tabular}

4. Findings Of Objective 4 ( To investigate the current level of innovative practices among SMEs in Johor)

Normality test was shown by using Kolmogorov-Smirnov because it was suitable for the sample size exceeded 50 respondents. normality analysis shows that all the significant value of variables is lower than 0.05 . This indicated that the data is not normally distributed. Therefore, Sperman Correlation analysis was used to identify the direction and the strength of the relationship that exist between all variables and innovation practices among SMEs in Johor.

Table VI. Result Of Sperman Correlation Analysis For Hypothesis.

\begin{tabular}{lll}
\hline & & $\begin{array}{l}\text { Innovation } \\
\text { Practices }\end{array}$ \\
\hline \multirow{4}{*}{ Financial Resources } & Sperman Correlation, r & $0.429^{* *}$ \\
& Significant, P & 0.000 \\
& Frequency, N & 152 \\
\hline Government Support & Sperman Correlation, r & $0.507^{* *}$ \\
Development & Significant, P & 0.000 \\
& Frequency, N & 152 \\
\hline Market Dynamic & Sperman Correlation, r & $0.489^{* *}$ \\
& Significant, P & 0.000 \\
& Frequency, N & 152 \\
\hline Academic-Industry & Sperman Correlation, r & $0.385^{* *}$ \\
Collaborations & Significant, P & 0.000 \\
& Frequency, N & 152 \\
\hline Management & Sperman Correlation, r & $0.519^{* *}$ \\
Orientation & Significant, P & 0.000 \\
& Frequency, N & 152 \\
\hline Organizational & Sperman Correlation, r & $0.434^{* *}$ \\
Culture & Significant, P & 0.000 \\
& Frequency, N & 152
\end{tabular}

**. Correlation is significant at the 0.01 level (2-tailed).
The hypothesizes posits that the six factors (Financial Resources, Government Support Development, Market Dynamic, Academic-Industry Collaborations, Management Orientation, Organizational Culture) have a significant positive relationship with a company's innovation practices. Based on Table VI the P-value is 0.000 for all factors which are lower than the correlation coefficient significant value 0.01 ( 2-tailed ). Then the six hypothesizes is supported and $\mathrm{H}$ null is rejected. Therefore, this indicates that there is a positive relationship between (Financial Resources, Government Support Development, Market Dynamic, Academic-Industry Collaborations, Management Orientation, Organizational Culture) and innovation practices among SMEs in Johor.

\section{DISCUSSION AND RECOMMENDATIONS}

\section{A. Research Question I}

In the case of the Johor environment was examined four factors to recognize the level of external business success factors being implemented by the SMEs in Johor.

Based on the 152 respondent of SMEs in Johor, the Academic-Industry Collaboration recorded 3.772 was the highest mean among other factors. According to (47) the value of mean is considered high, that shows the AcademicIndustry Collaboration such as Access to qualified graduates, Access to research institutions, collaborativeresearch, technology-transfer platforms, and Academic periodic workshops. From the point of view of respondents, these were the top things that helped their organizations succeed in innovation and achieve the desired goal.

The market dynamics, which came in the second position with mean recorded was 3.682 The mean also shows that it is a high value in interpreting the impact on the success of innovation in the company. The most important elements that have been questioned about the dynamics of the market is the access to great significance resources/components through effective relationships with suppliers, the understanding of the conditions of market demand and consumer trends, the Effectiveness of the market penneyvatienaptraticesnd healthy competition and the existence of exit Mechanisms to sell successful companies in the market.

Then came in the third factor the government support development that was recorded its mean value 3.574. Its interpreted as medium level. The least factor of the four factors is the financial resources, with the mean recorded 3.462 which is the lowest of all factors.

\section{B. Research Question II}

According to 152 respondent of SMEs in Johor, the Organizational Culture that recorded 3.912 was the highest mean among internal factors. According to (47), the value of mean consider high. that interpreting shows the organizational Culture one of many factors have been shown to be determinants for supporting innovative practice. Managers should pay more attention to their organizational culture if they follow innovation strategies. The

Published By:
Blue Eyes Intelligence Engineering
\& Sciences Publication


organizational culture of the company has an impact on the innovation practices and it also influences the way to apply the innovative solutions (34).

\section{Research Question III}

Based on 152 responses from SMEs in Johor, the result was that the current level of innovation was medium with a mean of 3.531. This result shows that the innovation among SMEs in Johor is not bad but also not good, especially with the many initiatives launched by the Malaysian government to encourage small and medium enterprises such as The Economic Transformation Programmed (2011-2020), Tenth Malaysia Plan (10MP):2011-2015, and Strategic Goals of the SMEs Master Plan. This is due to the many challenges facing SMEs in Malaysia, such as the lack of skilled workers and technical expertise, the few innovations or noninnovation through research and development ( $R$ \& D), limited economies of scale and the difficulty of eliminating traditional methods. Many SMEs do not pay enough attention to improving their skills or knowledge of the workforce or are reluctant to take advantage of governmentsponsored programmer training (48).

\section{Research Question IV}

Under this question, six research hypotheses are examined to identify external and internal factors that affect the innovation practices of SMEs in Johor, that are: Financial Resources (H1A), Government Supported Developments (H1B), Market Dynamics (H1C), AcademiaIndustry Collaborations (H1D), Management Orientation (H2A), and Organizational Culture (H2B).

\section{Financial Resources (H1A)}

This study has shown that there was a significant positive relationship, with a strong correlation between financial resources and innovation practices. The findings have shown a strong correlation coefficient with innovative practices, in which R-value was observed to be 0.429 and $\mathrm{P}$-value were 0.000 . The positive relationships obtained in this study indicate that the innovation practices will increase proportionally to the increase in financial resources. These findings were consistent with previous studies that discussed in the literature review (22-24), that also found there a significant positive relation among financial resources with innovation practices.

The foundation of the impact there is more facility for SMEs in Malaysia to get grants, credits, allocated capital from government agencies and financial institutions such as SMEs bank, Which provides loans and financing to SMEs to support their projects.

\section{Government Supported Developments (H1B)}

This study has shown that there was a significant positive relationship, with a strong correlation between governmentsupported developments with innovation practices. The findings have shown a strong correlation coefficient with innovative practices, in which R-value was observed to be 0.507 and $\mathrm{P}$-value was 0.000 . The positive relationships obtained in this study indicate that the innovation practices will increase proportionally to the increase in governmentsupported developments.

These findings were consistent with previous studies that discussed in the literature review (25-27), that also found there a significant positive relation among governmentsupported developments with innovation practices.

The government support comes from numerous government initiatives and development plans such as SMIDEC, which was recognized to promote the improvement of SMEs through financial support, suggested services, infrastructure facilities, market access, and other support programs. Its objective was to develop small and medium enterprises in Malaysia to be competitive in the global market. In 2004, the establishment of the National SME Development Council of (NSDC) introduced another chapter in the development of SMEs in Malaysia. As the highest policy-making body. These initiatives and actions have helped SMEs to increase their innovations and have helped them grow and strengthen their position in the market.

\section{Market Dynamics (H1C)}

This study has shown that there was a significant positive relationship, with a strong correlation between Market Dynamics and innovation practices. The findings have shown a strong correlation coefficient with innovative practices, in which R-value was observed to be 0.489 and $\mathrm{P}$-value were 0.000 . The positive relationships obtained in this study indicate that the innovation practices will increase proportionally to the increase in Market Dynamics.

These findings were consistent with previous studies that discussed in the literature review $(26,28-30)$, that also found there a significant positive relationship among market dynamics with innovation practices The foundation of the impact is that SMEs in the Johor market have access to quality resources and components through a deal with suppliers and understanding the requirements of the consumer orientations and market the situation and the efficiency of the antitrust policy.

\section{Academia-Industry Collaborations (H1D)}

This study has shown that there was a significant positive relationship, with a strong correlation between AcademiaIndustry Collaborations with innovation practices. The findings have shown a strong correlation coefficient with innovative practices, in which R-value was observed to be 0 . 385 and $\mathrm{P}$-value was 0.000 . The positive relationships obtained in this study indicate that the innovation practices will increase proportionally to the increase in AcademiaIndustry Collaborations. These findings were consistent with previous studies that discussed in the literature review (22, $31-35$, 49), that also found the significant positive relationship between academic-industry collaborations and innovation practices.

The positive relationship between these structures can have a positive impact on companies that play the role of government policy creativity to launch protuberant academic / research organizations, technology transfer centers, and specialized groups, and promote cooperation among the academic community and the business and the role of academics. organizations in this area. Support the

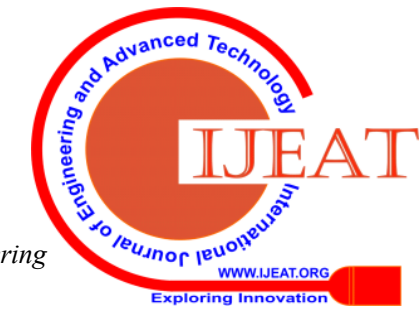


improvement of SMEs and their businesses through partnerships and innovation.

\section{Management Orientation (H2A)}

This study has shown that there was a significant positive relationship, with a strong correlation between Management Orientation and innovation practices. The findings have shown a strong correlation coefficient with innovative practices, in which R-value was observed to be 0.519 and $\mathrm{P}$-value were 0.000 . The positive relationships obtained in this study indicate that the innovation practices will increase proportionally to the increase in Management Orientation. These findings were consistent with previous studies that discussed in the literature review $(27,34,37-39)$, that also found there a significant positive relation among management orientation with innovation practices

The basis for the big impact is that entrepreneurs, SMEs and strategic way to generate or adopt innovation play vital roles, that are integrated into the integration of innovations as strategic objectives and future aspirations of their companies in the market, with a focus on management. Explore new opportunities, proactively engage in new initiatives and allocate resources to research and development activities, where managers can be more receptive to resource allocation to find appropriate strategies adapted to their environment that aim to identify new trends and integrate new knowledge into their existing companies' capabilities; And business performance.

\section{Organizational Culture (H2B)}

This study has shown that there was a significant positive relationship, with a strong correlation between Organizational Culture and innovation practices. The findings have shown a strong correlation coefficient with innovative practices, in which $\mathrm{R}$-value was observed to be 0 . 434 and $\mathrm{P}$-value were 0.000 . The positive relationships obtained in this study indicate that the innovation practices will increase proportionally to the increase in Organizational Culture. These findings were consistent with previous studies discussed in the literature review $(27,40-42)$, that also found there a significant positive relationship among organizational culture with innovation practices.

The foundation of the positive impact is the existence of a supportive domestic culture in SMEs to support and adopt innovative tactics (i.e. generate and follow ideas, think freely, learn from involvement and risk), learning procedures (admit new and ideas from outside and share new knowledge and skills) flexible even with its strong management orientation to innovation practices.

\section{E. Research Limitations}

These limits may affect the general relativity of the study and its validity and, taken together, may provide greater opportunities for upcoming research. These limits are linked to:

1) The study response rate was $41.75 \%$ of SMEs. This data was collected from various sectors, the generalizability of the results is imperfect, like other sorts of organizations such as non-profit is not included.

2) The study selected only a few internal and external factors. The framework model examined might not contain all the vital dimensions and factors linked with SMEs innovation practices.

3) This study has been in the Johor market and its conclusions can not apply to other states within Malaysia or to other countries because of administrative and organizing practices may differ according to different socio-economic cultures.

\section{F. Study Recommendations}

The study recommendations encourage research in the future. These proposed topics are discussed below:

1) Apply this study in other states within Malaysia and in neighboring countries and other countries, that possess a big number of SMEs and are undertaken to support innovation activities.

2) Comparing innovative practices of locally managed SMEs and SMEs managed by foreign entities can increase our understanding of SME innovation practices.

3) The study focused on SMEs, may better to investigate large companies and determine whether they have similar outcomes for SMEs.

\section{REFERENCES}

1. Szirmai A, Naudé W, Goedhuys M. Entrepreneurship, innovation, and economic development: Oxford University Press; 2011.

2. Kapetaniou C, Lee SH. Geographical proximity and open innovation of SMEs in Cyprus. Small Business Economics. 2019:1-16.

3. Naranjo-Valencia JC, Calderón-Hernández G, JiménezJiménez D, Sanz-Valle R. Entrepreneurship and innovation: Evidence in colombian SMEs. Handbook of Research on Intrapreneurship and Organizational Sustainability in SMEs: IGI Global; 2018. p. 294-316.

4. Omar SSb, Arokiasamy L, Ismail M. The background and challenges faced by the small medium enterprises. A human resource development perspective. International Journal of business and Management. 2009;4(10):P95.

5. Aziz NNA, Samad S. Innovation and competitive advantage: Moderating effects of firm age in foods manufacturing SMEs in Malaysia. Procedia Economics and Finance. 2016;35:256-66.

6. Halim HA, Ahmad NH, Ramayah T, Hanifah H, Taghizadeh SK, Mohamad MN. Towards an innovation culture: Enhancing innovative performance of Malaysian SMEs. Academic Journal of Interdisciplinary Studies. 2015;4(2):85.

7. Tajasom A, Hung DKM, Nikbin D, Hyun SS. The role of transformational leadership in innovation performance of Malaysian SMEs. Asian Journal of Technology Innovation. 2015;23(2):172-88.

8. Ale Ebrahim N, Ahmed S, Taha Z. SMEs; Virtual research and development (R\&D) teams and new product development: A literature review. International Journal of the Physical Sciences. 2010;5(7):916-30.

9. Zakariaa N, Abdullaha NAC, Yusoffa RZ, editors. The innovation-performance linkage: Empirical evidence of Malaysian manufacturing SMEs. International Soft Science Conference; 2016.

10. Lichtenthaler U, Lichtenthaler E. A capability-based framework for open innovation: Complementing absorptive capacity. Journal of management studies. 2009;46(8):1315-38 
11. Khan MWJ, Khalique M. An overview of small and medium enterprises in Malaysia and Pakistan: past, present and future scenario. Business and Management Horizons. 2014;2(2):38-49.

12. Rosli MM, Sidek S. The Impact of Innovation on the Performance of Small and Medium Manufacturing Enterprises:: Evidence from Malaysia. Journal of Innovation Management in Small \& Medium Enterprises. 2013;2013:1.

13. Brem A, Voigt K-I. Integration of market pull and technology push in the corporate front end and innovation management-Insights from the German software industry. Technovation. 2009;29(5):351-67.

14. Tidd J, Bessant J, Pavitt K. Managing innovation integrating technological, market and organizational change: John Wiley and Sons Ltd; 2005.

15. Crossan MM, Apaydin M. A multi-dimensional framework of organizational innovation: A systematic review of the literature. Journal of management studies. 2010;47(6):1154-91.

16. Hogan SJ, Soutar GN, McColl-Kennedy JR, Sweeney JC. Reconceptualizing professional service firm innovation capability: Scale development. Industrial marketing management. 2011;40(8):1264-73.

17. Sefiani Y. Factors for success in SMEs: a perspective from Tangier: University of Gloucestershire; 2013.

18. Bullen PA. Adaptive reuse and sustainability of commercial buildings. Facilities. 2007;25(1/2):20-31.

19. Saleh AS, Ndubisi NO. An evaluation of SME development in Malaysia. International review of business research papers. 2006;2(1):1-14.

20. Broome B. Driving Arizona's global economy. Economic Development Journal. 2007;6(2):26.

21. Jaruzelski B, Moujaes CN, Eltayeb R, Hajj J. Coherent Linkages How to Foster Innovation-Based Economies in the Gulf Cooperation Council. Booz \& Co Publication. 2013.

22. Wonglimpiyarat J. Government programmes in financing innovations: Comparative innovation system cases of Malaysia and Thailand. Technology in Society. 2011;33(1-2):156-64.

23. Ayyagari M, Demirgüç-Kunt A, Maksimovic V. Firm Innovation in Emerging Markets World Bank Policy Research Working Paper 4157. Washington, DC: World Bank. 2007.

24. Talke K, Salomo S, Kock A. Top management team diversity and strategic innovation orientation: The relationship and consequences for innovativeness and performance. Journal of Product Innovation Management. 2011;28(6):819-32.

25. Radas S, Božić L. The antecedents of SME innovativeness in an emerging transition economy. Technovation. 2009;29(6-7):438-50.

26. Zhu Y, Wittmann X, Peng MW. Institution-based barriers to innovation in SMEs in China. Asia Pacific Journal of Management. 2012;29(4):1131-42.

27. Forsman H. Innovation capacity and innovation development in small enterprises. A comparison between the manufacturing and service sectors. Research Policy. 2011;40(5):739-50

28. Dal Zotto C, Sacco V, Schenker Y. Market Structure and Innovation Policies in Switzerland. Innovation Policies in the European News Media Industry: Springer; 2017. p. 205-18.

29. Norbäck P-J, Persson L. Entrepreneurial innovations, competition and competition policy. European Economic Review. 2012;56(3):488-506.

30. Nemet GF. Demand-pull, technology-push, and government-led incentives for non-incremental technical change. Research policy. 2009;38(5):700-9.
31. Nelson AJ. Managing collaborations at the universityindustry interface: An exploration of the diffusion of PCR and rDNA. 2015.

32. Wright $R$. How to get the most from university relationships. MIT Sloan Management Review. 2008;49(3):75.

33. Xu Q, Chen J, Xie Z, Liu J, Zheng G, Wang Y. Total Innovation Management: a novel paradigm of innovation management in the $21 \mathrm{st}$ century. The Journal of Technology Transfer. 2007;32(1-2):9-25.

34. Teece DJ. Technological innovation and the theory of the firm: the role of enterprise-level knowledge, complementarities, and (dynamic) capabilities. Handbook of the Economics of Innovation. 1: Elsevier; 2010. p. 679-730.

35. Haour G, Miéville L. From science to business: how firms create value by partnering with universities: Palgrave Macmillan; 2011.

36. Avlonitis GJ, Gounaris SP. Marketing orientation and its determinants: an empirical analysis. European journal of marketing. 1999;33(11/12):1003-37.

37. Dibrell C, Craig JB, Hansen EN. How managerial attitudes toward the natural environment affect market orientation and innovation. Journal of Business Research. 2011;64(4):401-7.

38. Nooteboom B. Innovation and diffusion in small firms: theory and evidence. Small Business Economics. 1994;6(5):327-47.

39. Blumentritt T, Danis WM. Business strategy types and innovative practices. Journal of Managerial Issues. 2006:274-91

40. Nadler D, Tushman M, Tushman ML, Nadler MB. Competing by design: The power of organizational architecture: Oxford University Press; 1997.

41. Hjalager A-M. A review of innovation research in tourism. Tourism management. 2010;31(1):1-12.

42. Freel MS. Where are the skills gaps in innovative small firms? International journal of entrepreneurial behavior \& research. 1999;5(3):144-54.

43. Al-Ansari Y, Pervan S, Xu J. Innovation and business performance of SMEs: the case of Dubai. Education, Business and Society: Contemporary Middle Eastern Issues. 2013;6(3/4):162-80.

44. Krejcie RV, Morgan DW. Determining sample size for research activities. Educational and psychological measurement. 1970;30(3):607-10.

45. Sekaran U. Research Methods For Business, A Skil Building Approach, John Willey \& Sons. Inc New York. 2003.

46. Bernard HR, Bernard HR. Social research methods: Qualitative and quantitative approaches: Sage; 2012.

47. Robins J, Wiersema MF. A resource-based approach to the multibusiness firm: Empirical analysis of portfolio interrelationships and corporate financial performance. Strategic management journal. 1995;16(4):277-99.

48. Musa H, Chinniah M. Malaysian SMEs development: future and challenges on going green. Procedia-Social and Behavioral Sciences. 2016;224:254-62.

49. Kamalian A, Rashki M, Arbabi ML. The relationship between information system (IS) innovation and innovation among Iranian small and medium enterprises (SMEs). African Journal of Business Management. 2013;7(9):693-700.

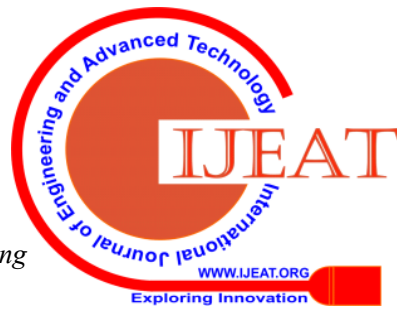

